\title{
Pharmacotherapy in heart failure patients with reduced ejection fraction - results from clinical practice
}

\author{
(D)Anto Stažićc ${ }^{12}$, \\ (DMirna Doknjaš², \\ (D) Jerko Arambašić', \\ (D) Kristina Kralik² \\ DKristina Selthofer- \\ Relatić $^{1,2}$
}

'University Hospital Centre Osijek, Osijek, Croatia 2University Josip Juraj Strossmayer Osijek, Faculty of Medicine, Osijek, Croatia

\section{RECEIVED:}

December 5, 2020

ACCEPTED:

December 18, 2020

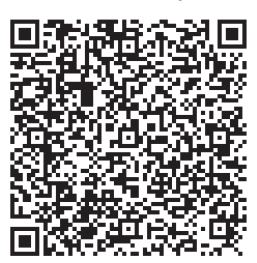

$\square$ Cardiologia Croatica 2021;16(1-2):28.
KEYWORDS: dose, heart failure with reduced ejection fraction hospitalization, pharmacotherapy. CITATION: Cardiol Croat. 2021;16(1-2):28. | https://doi.org/10.15836/ccar2021.28

*ADDRESS FOR CORRESPONDENCE: Anto Stažić, Klinički bolnički centar Osijek, Josipa Huttlera 4, HR-31000 Osijek, Croatia. / Phone: +385-95-3877-276 / E-mail: anto.stazic1@gmail.com

ORCID: Anto Stažić, https://orcid.org/0000-0002-4429-8297 • Mirna Doknjaš, https://orcid.org/0000-0002-2915-7533 Jerko Arambašić, https://orcid.org/0000-0002-7441-2097 • Kristina Kralik, https://orcid.org/0000-0002-4481-6365 Kristina Selthofer-Relatić, https://orcid.org/0000-0002-9890-6489

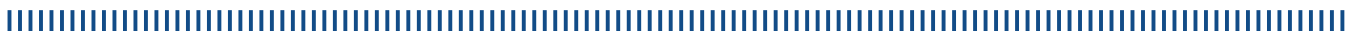

Introduction: The aim of the study was to establish pharmacotherapy application in the treatment of HFrEF (heart failure with reduced ejection fraction) patients in regular clinical practice, according to the European Society of Cardiology guidelines for acute and chronic heart failure $2016^{1}$.

Patients and Methods: The study included 127 patients of both sexes (41\% female, mean age 80; 59\% male, mean age 68, p=0.001), hospitalized in 2019 at the Department for Heart and Vascular Diseases, Osijek University Hospital, due to HFrEF NYHA IV. It follows their first, second, and third hospitalizations. All the patients' data, including HFrEF etiology; biochemical, hemodynamic, and echocardiographic parameters; and pharmacotherapy data, were collected from the hospital database.

Results: Crucial comorbidities for HFrEF, such as arterial hypertension, were present in $83 \%$ of patients. Diabetes mellitus type II was found in $39 \%$ patients, and coronary heart disease in $57.5 \%$ of patients. In the first hospitalization (median NT-proBNP value $4276 \mathrm{pg} / \mathrm{ml}$ ), discharge therapy included 54\% BB, 60\% ACEI, 52\% MRA (50\% 50mg), 32\% ARNI (25\% 49/51mg twice daily), 49\% statins. In the second hospitalization (median NT-proBNP $5636 \mathrm{pg} / \mathrm{ml}$ ), discharge therapy included 26\% BB, 22\% ACEI, 25\% MRA (25\% 50mg), 29\% ARNI (50\% 49/51mg twice daily), 24\% statins. In the third hospitalization (median NTproBNP $8998 \mathrm{pg} / \mathrm{ml}$ ), discharge therapy included 10\% BB, 10\% ACEI, 12\% MRA (25\% 50mg), 21\% ARNI (25\% 49/51mg twice daily), 14\% statins. A negligible number of patients were treated with ATII blockers and SGLT2 inhibitors.

Conclusion: HFrEF patients were already treated in outpatient clinics because of comorbidities and established HFrEF during stabile phase of disease. After the first hospitalization, they had the best pharmacologic profile for HFrEF treatment (except ARNI group, higher dose in the second hospitalization). HFrEF worsening in each next hospitalization that followed, resulting in lower quality pharmacotherapy, probably as a result of patients' worse clinical, hemodynamic, and biochemical condition. Early medication of HFrEF treatment in stabile phase of the disease is crucial for HFrEF prognosis.

LITERATURE IIIIIIIIIIIIIIIIIIIIIIIIIIIIIIIIIIIIIIIIIIIIIIIIIIIIIIIIIIIIIIIIIIIIIIIIIIIIIIIIIIIIIIIIIIIII

1. Ponikowski P, Voors AA, Anker SD, Bueno H, Cleland JGF, Coats AJS, et al; ESC Scientific Document Group. 2016 ESC Guidelines for the diagnosis and treatment of acute and chronic heart failure: The Task Force for the diagnosis and treatment of acute and chronic heart failure of the European Society of Cardiology (ESC)Developed with the special contribution of the Heart Failure Association (HFA) of the ESC. Eur Heart J. 2016 Jul 14;37(27):2129-2200. https://doi.org/10.1093/eurheartj/ehw128 